\title{
Ley de Procedimiento de la Jurisdicción Especial para la Paz: aciertos, debilidades y desafíos del derecho penal en contextos de justicia transicional
}

The Procedural Law of the Special Jurisdiction for Peace: Strengths, Weaknesses and Challenges of Criminal Law in Transitional Justice Contexts

Kai Ambosa ${ }^{\text {a }}$

University of Göttingen, Alemania

kambos@gwdg.de

ORCID: http://orcid.org/0000-0003-3597-2443
DOI: https://doi.org/10.11144/Javeriana.vj69.lpje

Publicación: 30 de junio de 2020

La sección especial de la revista Vniversitas, publicada en el volumen 69, recoge nueve artículos producto de varias investigaciones y reflexiones individuales sobre la Jurisdicción Especial para la Paz (JEP), elaboradas por las expertas y expertos que participaron en el seminario realizado los días 27 y 28 de mayo de 2019 en las instalaciones de la Facultad de Ciencias Jurídicas de la Pontificia Universidad Javeriana de Bogotá. Tanto el seminario, el cual se enmarcó también en el ciclo de seminarios del Centro de Estudios de Derecho Penal y Procesal Penal Latinoamericano (CEDPAL) de la Universidad de Göttingen y en el que participé como moderador y comentarista, así como la publicación de estos trabajos hacen parte del proyecto titulado "Ley de Procedimiento de la Jurisdicción Especial para la Paz: aciertos, debilidades y desafíos del derecho penal en contextos de justicia Transicional”, seleccionado y financiado por el Instituto Colombo-Alemán para la Paz (CAPAZ), en el marco de la convocatoria "Estudios Exploratorios 2018".

Los retos que debe afrontar el derecho penal en contextos de justicia transicional, en especial desde el punto de vista procesal, representó el problema central que aquí se quiso abordar. En este sentido, se examinó qué aspectos podrían ser considerados como los principales aciertos, así como cuáles podrían ser las debilidades y los desafíos más apremiantes de las disposiciones recogidas en la Ley de Procedimiento de la JEP, a la luz de los diferentes estándares establecidos por el derecho nacional e internacional. Sin embargo, las reflexiones plateadas por las personas invitadas al seminario, así como las discusiones sostenidas en él, demostraron rápidamente que incluso los aspectos más operativos de la JEP requieren un abordaje amplio, en el que no se pierda de vista la complejidad del sistema de justicia transicional del cual hace parte, ni el contexto político y social en el que surgió.

Se trata, en otras palabras, de un mecanismo judicial de justicia transicional, para cuyo entendimiento resulta fundamental reconceptualizar elementos tradicionales del derecho penal sustancial y procesal, con el fin de conectarlos con perspectivas alternativas, provenientes, por ejemplo, del paradigma de la justicia restaurativa. Estos debates suponen entonces combinar diferentes tipos de metodologías y enfoques, con el fin de establecer diálogos que desde diferentes orillas contribuyan a entender mejor el gran reto que debe afrontar la JEP en la construcción de paz, así como a redimensionar las expectativas frente a su trabajo y tomar consciencia de sus límites. Por esto, en los artículos reunidos en este número especial se presentan estudios teóricos, dogmático-normativos, empíricos e incluso con perspectiva comparada. Quienes consulten estos trabajos no solo encontrarán explicaciones relacionadas en estricto sentido con temas procesales, mas bien tendrán la oportunidad de adentrarse tanto en discusiones generales sobre la naturaleza misma de la JEP y los principios que la orientan, como en los pormenores de algunos problemas más concretos, pero decisivos para el éxito de esta jurisdicción.

Notas de autor

a Autor de correspondencia. Correo electrónico: kambos@gwdg.de 
Los artículos publicados en este número especial se pueden dividir en cuatro partes. En la primera parte se encuentran dos estudios que permiten poner en perspectiva las discusiones sobre la JEP. En el primero de ellos, "Las disputas por la Jurisdicción Especial para la Paz (JEP): una reflexión crítica sobre su sentido político y jurídico", Gabriel Ignacio Gómez reconstruye el contexto sociopolítico en el que fue creada la JEP e identifica los discursos críticos y de apoyo que entraron en tensión durante este proceso e influyeron en su formación. En el segundo estudio, titulado "El Tribunal para la Paz y las Salas de Justicia de la JEP como órganos jurisdiccionales sui generis", Diego Tarapués reflexiona sobre la naturaleza institucional de la JEP como juez natural del conflicto armado colombiano, con competencia prevalente y preferente.

En la segunda parte, se encuentran tres investigaciones que se concentran en aspectos procesales más concretos y en las que se discute principalmente sobre el papel de las víctimas en el esquema procesal de la JEP, especialmente en casos de reconocimiento de responsabilidad. Así, Gustavo Cote, en "El carácter dialógico del proceso con reconocimiento de responsabilidad ante la Jurisdicción Especial para la Paz: retos del derecho penal en contextos de justicia transicional", contrasta la estructura normativa del proceso con reconocimiento de responsabilidad con la práctica de la JEP decantada hasta el momento, con el fin de establecer el significado del principio dialógico. Lorena Vega, a su turno, muestra en "Participación de las víctimas en la JEP: especial referencia a los informes de las organizaciones de víctimas, étnicas y de derechos humanos" la manera como las víctimas han logrado participar en la apertura de procesos mediante la presentación de informes, así como las dificultades que éstas han tenido que afrontar al acudir a dicho mecanismo. Y, Juliette Vargas, en "Participación colectiva de víctimas ante la jurisdicción especial para la paz (JEP)", discute esta forma de participación de víctimas con perspectiva comparada, tomando como base algunas experiencias internacionales, para advertir sobre los retos de esta alternativa.

La tercera parte la componen dos trabajos en los que se discute sobre aspectos estructurales y de organización de la labor realizada por la JEP. El primero de estos trabajos se titula "Justicia restaurativa y reparación: desafíos de la JEP frente a una relación en construcción”. Aquí, Juana Acosta y Cindy Vanessa Espitia problematizan el concepto de justicia restaurativa, teniendo en cuenta el principio de integralidad y la manera como la JEP se articula o debe articular con otros componentes del sistema de justicia transicional. En el segundo trabajo, "La selección y priorización de casos en la Jurisdicción Especial para la Paz", elaborado por Nelson Camilo Sánchez y Alejandro Jiménez, se analiza el desarrollo político y normativo que estos dos instrumentos de racionalización de la persecución penal han tenido en Colombia, para mostrar cómo fueron incluidos genérica y vagamente en el Acuerdo de Paz y que su desarrollo normativo ha sido paulatino y accidentado.

La cuarta parte reúne los dos últimos artículos que aparecen en este número especial. Estos dos estudios, tal vez con un acento más teórico, se enfocan con mayor fuerza en la dimensión penal de la JEP y discuten sobre los fines que las sanciones están llamadas a cumplir en este contexto. En "De la privación a la restricción de la libertad y otras sanciones penales. ¿hacia un paradigma restaurativo en la justicia especial para la paz colombiana?" Norberto Hernández compara diferentes modelos punitivos y llama la atención sobre el rol de la reparación en el modelo sancionatorio de la JEP. Mientras, en "Las funciones del derecho penal y de la justicia transicional en la jurisdicción especial para la paz" Carlos Castro reflexiona sobre la manera en que el derecho penal puede contribuir a la consecución de los fines de la justicia transicional.

Por supuesto, este proyecto no se hubiera podido realizar sin la colaboración y el trabajo mancomunado de varias personas e instituciones. En este sentido debo agradecer en primer lugar al Instituto CAPAZ, por haberlo seleccionado y apoyado con paciencia hasta el final. También a las profesoras Lorena Vega (Universidad Javeriana) y María Cristina Gómez (Universidad de Antioquia), así como al Profesor Gustavo Cote (Universidad Javeriana), con quienes presentamos la propuesta inicial. De la misma manera, debo mencionar a Julio Andrés Sampedro, quien como Decano de la Facultad de Ciencias Jurídicas se comprometió desde un principio con la publicación de los resultados del proyecto; a Carlos Andrés Uribe, editor general de la revista Vniversitas, y a Javier Celis, Coordinador Editorial, sin cuya colaboración no hubiera sido posible 
la publicación de este número especial. Para terminar, debo agradecer a los autores y autoras que aceptaron contribuir con la elaboración de los estudios que en este número entregamos a la comunidad académica nacional e internacional y ponemos a disposición del público en general. De esta manera, esperamos incentivar la discusión sobre la forma como en Colombia se tramita jurídicamente el posconflicto y, por qué no, contribuir a la implementación del Acuerdo de Paz.

\section{Licencia Creative Commons CC BY 4.0}

Cómo citar este editorial: Kai Ambos, Ley de Procedimiento de la Jurisdicción Especial para la Paz: aciertos, debilidades y desafios del derecho penal en contextos de justicia transicional, 69 Vniversitas (2020). https://do i.org/10.11144/Javeriana.vj69.lpje 